\title{
Internet:
}

\section{um novo paradigma de informação e comunicação}

Cibele Abdo Rodella Jornalista pós-graduada em Filosofia. Professora do curso de Comunicação Social do Cesumar (Centro Universitário de Maringá).

E-mail: cibeleabdo@aol.com.br

\section{As novas tecnologias da informação e da comunicação impulsionam a construção da cultura global}

\section{POTENCIALIDADES DAS NTIC}

O produto que melhor representa as potencialidades das Novas Tecnologias de Informação e Comunicação (NTIC) é a internet. Através da rede é possível se comunicar em tempo real com qualquer parte do globo terrestre e com um custo bastante reduzido, o que vem revolucionando, em seus mais variados aspectos, as relações em sociedade neste início de século - trabalho, política, economia, cultura. As NTIC podem ser consideradas como um dos fatores que têm possibilitado a construção de uma nova cultura neste novo milênio: a cultura global.

Foram as NTIC que permitiram, tecnicamente, o fenômeno político, econômico, social e cultural a que chamamos de globalização. Mesmo reconhecendo que o processo da globalização não é recente, o desenvolvimento das NTIC no século XX inflingiu um impulso ao processo de comunicação global jamais visto na história econômica e social de nossa civilização, principalmente nos últimos trinta anos do século passado.

É essa nova cultura, a global, que as NTIC, especialmente a Internet, vem permitindo consolidar, colocando em questão a construção de um novo paradigma informacional e comunicacional, o qual se vincula à definição da identidade do cidadão global - o usuário das NTIC - e à transformação do monopólio da informação pelas mídias tradicionais ante a interatividade. 
A pretensão deste artigo é apontar algumas questões para o novo paradigma e alertar sobre a necessidade de se realizar estudos mais aprofundados, principalmente por educadores e comunicadores, do papel das NTIC na configuração da sociedade moderna.

\section{INTERNET COMO PRODUTO SOCIAL}

A internet é fruto da dinâmica social que a criou. Neste sentido, não é somente um instrumento de elaboração, armazenamento e transmissão de informação, mas uma instituição inserida no contexto da sociedade contemporânea.

A sociedade estabelece uma relação dialética com a internet, permitindo a criação e o desenvolvimento do conteúdo da rede, ao mesmo tempo em que se produzem transformações substanciais na cultura da sociedade.

Uma alimenta a outra, e a síntese decorrente deste processo tem como um dos produtos o internauta - paradigma do homem globalizado.

O que compreendemos de mais importante no modelo de operação da internet é seu caráter descentralizado e interativo, o que possibilita romper a relação de quem detém o poder da informação, processo antes não imaginado pelos produtores das mídias tradicionais ${ }^{1}$. Esta nova configuração vem provocando mudanças significativas na esfera da produção simbólica, o que leva autores como o antropólogo Gustau Navarro i Barba a apontar mudanças na estrutura dos estados nacionais e na configuração da sociedade civil. "No momento que esta visão descentralizada (referindo-se à passagem do uso militar da internet para o civil) é passada à sociedade civil, traz graves problemas às estruturas de controle dos estados nacionais e acelera o processo de mundialização que os setores mais dinâmicos exigem desses mesmos estados. Este paradoxo entre os diversos grupos de poder abre brechas muito importantes que permitem a participação de setores que, apesar de estarem distantes dos centros de decisão econômica, têm uma formação técnica e intelectual que lhes permite

1. Referimo-nos às mídias tradicionais como sendo os impressos como jornal e revista e os meios de comunicação eletrônicos como o rádio e a televisão, antes do advento dos novos recursos tecnológicos.

2. NAVARRO i BARBA, Gustau. Hegemonía y subalternidad en la red internet (Hegemonia e subalternidade na internet). Disponível em:_<http:// www.naya.org.ar/articulos/ hegemon.htm>. Acesso em 12 jun. 2002.

3. THOMPSON, John B. Ideologia e cultura moderna. São Paulo: Vozes, 1995. Ver capítulo 2. criar novos espaços comunicacionais, iniciando-se uma ruptura da hegemonia das grandes empresas de comunicação. A internet oferece a possibilidade de emissão reduzindo-se drasticamente os custos dessa emissão; este fato oferece novas possibilidades àqueles que têm a capacidade de comunicar alguma coisa, ao não depender exclusivamente daqueles que têm a capacidade econômica para emitir mensagens nos sistemas tradicionais de comunicação"".

A partir do exposto por Navarro, lembramos que o conceito de sociedade civil também vem sendo posto em questão, já que deixa de ser entendida apenas como uma instituição organizada em entidades e associações dos mais variados tipos para apontar a participação solitária do cidadão, que se manifesta através dos novos espaços comunicacionais, o que mostra a necessidade do debate sobre a esfera pública, que não cabe neste artigo, mas para o qual recomendamos a leitura de Thompson ${ }^{3}$, que realiza um estudo fecundo a partir das considerações de Habermas. 


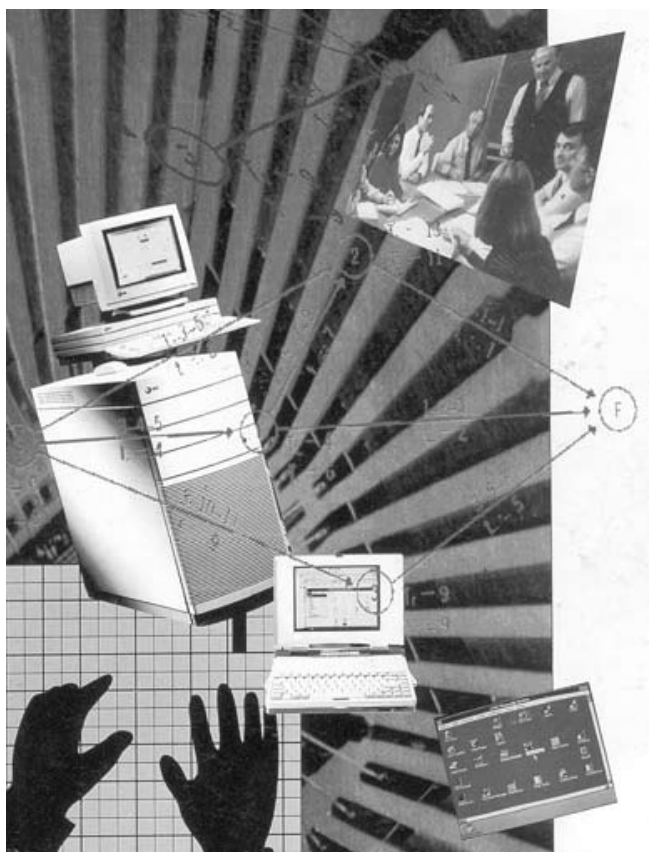

American Showcase

Por permitir a difusão democrática da informação, a Internet cria uma nova categoria de usuário, consumidor e emissor da informação, livre para escolher o tipo de mensagem a qual quer ter acesso e que deseja ele mesmo veicular. Permite também interatividade - o cidadão virtual é menos passivo, no sentido de possuir uma ferramenta que lhe possibilita participar das decisões, sejam locais ou mundiais, recriando o chamado espaço público, e estabelece o modelo de cidadão global.

Esse cidadão global vem exigindo - devido ao status de consumidor e emissor da informação - uma alteração no formato dos meios de comunicação de massa tradicionais que se estruturam em um modelo de informação vertical decorrência do controle da informação das grandes empresas de comunicação do centro gerador para as extremidades compostas de leitores e ouvintes.

Para não serem excluídas desse processo, as empresas jornalísticas, de entretenimento, rádios e TVs têm disponibilizado na rede suas versões on-line, buscando criar uma nova linguagem no novo meio, mas a maioria das recentes experiências sofre por falta de interatividade, principal característica da internet. O processo pelo qual as empresas de comunicação de massa estão se inserindo na web é bastante dinâmico, com altos e baixos, e em sua maioria ainda buscando uma linguagem própria e, principalmente, a forma como tais sites se viabilizarão economicamente.

Octávio Ianni expõe com muita propriedade que o advento da globalização como instrumento da lógica capitalista enseja um momento de insegurança e indagações cujas respostas ainda não estão de todo formadas e cujas conseqüências animam os mais variados debates. "A globalização do mundo expressa um novo ciclo de expansão do capitalismo, como modo de produção e processo 
civilizatório de alcance mundial. Um processo de amplas proporções envolvendo nações e nacionalidades, regimes políticos e projetos nacionais, grupos e classes sociais, economias e sociedades, culturas e civilizações. Assinala a emergência da sociedade global, como uma totalidade abrangente, complexa e contraditória. Uma realidade ainda pouco conhecida, desafiando práticas e ideais, situações consolidadas e interpretações sedimentadas, formas de pensamento e vôos de imaginação. Para reconhecer essa nova realidade, precisamente no que ela tem de novo, ou desconhecido, torna-se necessário reconhecer que a trama da história não se desenvolve apenas em continuidades, seqüências, recorrências. A mesma história adquire movimentos insuspeitados, surpreendentes. A mesma dinâmica das continuidades germina possibilidades inesperadas, hiatos inadvertidos, rupturas que parecem terremotos ${ }^{4}$."

Com a interatividade proporcionada pelos novos meios digitais e a organização, armazenamento e difusão da informação em rede global, qual o novo modelo comunicacional e informacional que se forma em substituição aos meios de comunicação clássicos?

\section{EM BUSCA DO NOVO PARADIGMA}

O fato de que a tecnologia de acesso à Internet tende a ficar mais barata e que o número de pessoas com acesso à rede irá se ampliar, cada vez mais resulta em um novo modelo ou paradigma que veio para transformar os meios de comunicação de massa tradicionais e sua estrutura de poder. Os usos dessa nova tecnologia ainda geram controvérsias, graças às milhares de possibilidades e suas múltiplas funções e conseqüências.

Daí o debate quanto aos efeitos e impactos para a sociedade como um todo, bem como as dúvidas quanto ao controle dos novos meios, e a capacidade de ampliar, democraticamente, o número de participantes da rede.

Em países como o Brasil, a discussão ainda é mais séria já que grande parte da população é composta de analfabetos ou analfabetos funcionais, que não têm acesso nem aos meios mais tradicionais de difusão da informação, como os impressos ${ }^{5}$.

A professora Ana Maria Fadul alerta, em estudo bastante conhecido sobre

4. IANNI, Octavio. A era do globalismo. Rio de Janeiro: Civilização Brasileira, 1997. p. 7.

5. Segundo levantamento FGV/RJ, $12,46 \%$ da população brasileira, em 2001, tinha acesso a computador em casa e 8,31\% navegava na Internet.

6. FADUL, Ana Maria. Novas tecnologias de comunicação: impactos políticos, culturais e socioeconômicos. São Paulo: Summus Editorial, 1986. p. 78. as novas tecnologias, sobre limitação de seu uso por amplas camadas da população e apresenta um diagnóstico negativo sobre esse uso. "Sente-se, mais uma vez, que o homem tem cada vez menos acesso à informação. Poucos conhecem verdadeiramente pelos meios de massa, e muito menos ainda, pode-se chegar ao conhecimento pelas novas tecnologias: o número aqui será ainda mais restrito. O que acontece, na verdade, é um aumento de controle dos cidadãos, que, desejosos de conhecer melhor, aceitam ser sócios de um sistema de invasão de consciências e domicílios, como é a ação de um computador, ligado da casa ao trabalho e vice-versa. Para que tudo isso seja camuflado, fala-se, muito mais agora, em democracia nas comunicações. Mas sabe-se que isto não é verdade ${ }^{6}$."

As opiniões se dividem sobre a verdadeira democratização do acesso às informações e sua difusão, bem como das vantagens da globalização, principalmente para os países chamados emergentes. 
Para haver uma sociedade global é necessário que tal sociedade se comunique entre si e produza cultura e identidade próprias, e que reconheça e transmita conceitos globais. Segundo $\mathrm{Levy}^{7}$, esse global não é totalizante, pois se faz e se refaz o tempo inteiro, colocando novos atores no cenário internacional, rompendo com o limite do cidadão enquanto ser pertencente a um estado nacional. Ser cidadão é cada vez mais interagir com todos os cidadãos universais. "Por meio dos computadores e das redes, as mais diversas pessoas podem entrar em contato, dar as mãos ao redor do mundo. Em vez de se construir com base na identidade do sentido, o novo universal se realiza por imersão. Estamos todos no mesmo banho, no mesmo dilúvio de comunicação. Não pode mais haver, portanto, um fechamento semântico ou uma totalização [...]. Quanto mais o novo universal se concretiza ou se atualiza, menos ele é totalizável. Ficamos tentados a dizer que se trata finalmente do verdadeiro universal, porque não se confunde mais com uma dilatação do local nem com a exportação forçada dos produtos de uma cultura particular ${ }^{8}$."

Nesse sentido, a informação será compartilhada e gerada em cadeia por todos que tenham um mínimo de capacidade de acesso à tecnologia e conhecimento tecnológico para participar da rede virtual de informação.

A Internet é uma alternativa às mídias de massa tradicionais. Permite que os usuários encontrem as informações que lhes interessa e coloquem em rede suas opiniões, pensamentos e versões dos fatos sem que precisem se submeter a filtros - tais como editores, jornalistas, empresas de comunicação. De tal modo, segundo Levy, as novas tecnologias de comunicação estimulam uma comunicação não-midiática, já que é "comunitária, transversal e recíproca".

Esse novo paradigma coloca a informação a serviço dos mais variados grupos de interesse, transformando a internet numa Torre de Babel onde tudo pode ser colocado, discutido, encontrado. Isso não significa que a internet não tenha uma cultura própria e limites para participação. Sabemos que muitos usuários têm forçado provedores a excluir da rede indivíduos que não respeitam alguns códigos de ética da nova mídia, tal como os difusores da pornografia infantil.

Discutem-se ainda os diferentes usos dessas tecnologias, e muitos condenam as NTIC acusando-as de desumanização. A exclusão de uma grande parcela da população mundial do campo das novas tecnologias é fato que deve ser discutido, mas condenar tais avanços tecnológicos, como alguns autores propõem, pela impossibilidade de acesso universal, é uma visão ingênua e limitadora da realidade.

Segundo Levy, trata-se de um direito moral a oportunidade de acesso às redes de informação, pelo que ela pode proporcionar de trocas de experiências, conhecimentos para a solução de muitas questões básicas para países do Terceiro Mundo ou em fase de desenvolvimento.

O que será dessa nova mídia dependerá muito do projeto que se queira moldar a ela e das discussões que cada sociedade irá promover localmente. É preciso reconhecer os problemas e as conseqüências dessa nova mídia para a humanidade, e para cada país especificamente. Como afirma Levy: "Não que-
7. LÉVY, Pierre. Cibercultura. São Paulo: Editora 34, 1999.

8. lbid., p. 119-120

9. Ibid., p. 224. 
ro de forma alguma dar a impressão de que tudo o que é feito com as redes digitais seja bom. Isso seria tão absurdo quanto supor que todos os filmes sejam excelentes. Peço apenas que permaneçamos abertos, benevolentes, receptivos em relação à novidade. Que tentemos compreendê-la, pois a verdadeira questão não é ser contra ou a favor, mas sim reconhecer as mudanças qualitativas na ecologia dos signos, o ambiente inédito que resulta da extensão das novas redes de comunicação para a vida social e cultural. Apenas dessa forma seremos capazes de desenvolver estas novas tecnologias dentro de uma perspectiva humanista" ${ }^{10}$.

\section{MUDANÇAS CULTURAIS}

Os meios de comunicação de massa (rádio, TV, cinema e impressos) modificaram os parâmetros culturais e estéticos da segunda metade do século passado, influenciando decididamente a formação de uma nova cultura urbana e a da chamada sociedade civil, incidindo de maneira decisiva nos processos das identidades nacionais.

As NTIC vêm provocando o mesmo fenômeno. A possibilidade de acesso e a troca de conteúdos amplos (sem entrarmos aqui na discussão da qualidade desse conteúdo) proporcionam aos usuários das NTIC, especificamente da internet, a possibilidade de construção de espaço comunicacional autônomo, sem dependência do conteúdo veiculado pela mídia. Nesse sentido é preciso perceber que a transformação na esfera cultural atinge não só as instituições nacionais, mas a própria vida cotidiana, e a compreensão desse processo exige entender como essas transformações se dão no dia-a-dia do usuário da rede.

Podemos inferir que uma nova identidade está sendo forjada, o que exige um esforço de compreensão pelas Ciências Sociais. Thompson ${ }^{11}$ acredita que na sociedade moderna a constituição da identidade é um ato cada vez mais particular, pessoal, de cada indivíduo (graças aos meios de comunicação), embora não desconsidere os condicionamentos sociais e as desigualdades de recursos e oportunidades para a constituição do self (eu).

Moraes afirma ainda que: "queiramos ou não, a vida cotidiana, as mentalidades, a sociabilidade e o trabalho passam por mudanças radicais diante da convergência de circuitos digitais, satélites e fibras ópticas. [...] uma nova ordem comunicacional se instaura na interseção de dois vetores: a) a contínua absorção, pelos grandes conglomerados midiáticos, de dispositivos de última geração, interligados em redes e geradores de informações on-line e/ou em tempo real

10. Ibid., p. 12.

11. THOMPSON, John B. A mídia e a modernidade. 4. ed. São Paulo: Vozes, 2002.

12. MORAES, Dênis de. Globalização, mídia e cultura contemporânea. Campo Grande: Letra Livre, 1997. p. 19. de amplíssimo alcance; b) o ciberespaço como um âmbito desterritorializado de bases cooperativas, de trocas interativas e de acessos instantâneos a uma multiplicidade infinita de saberes. No contexto de economia globalizada e de cultura mundializada que caracteriza o capitalismo tardio, as tecnologias propiciam ao campo da comunicação um dinamismo sem precedentes. Elas tornam disponível, a camadas ponderáveis de audiência, um estoque inimaginável de dados e imagens, de opções de entretenimento e de simulacros. Os aparatos de divulgação disponibilizam signos sociais que assumem significação mundial"12. 
Fazer uma análise do fenômeno da rede mundial dos computadores e a transformação que irá provocar nos modelos de consumo e emissão da informação pelos indivíduos, leva-nos à necessidade de conceituar o problema em seus fundamentos e apontar as transformações desses conceitos à luz de um novo momento histórico. Vale ressaltar que os indivíduos, mundiais, estão buscando conquistar um papel de maior autonomia na escolha do conteúdo da informação que eles desejam absorver, ao mesmo tempo que o uso das NTIC permite o crescimento exponencial da transmissão e conseqüentemente o raio de operação da ideologia na sociedade moderna, como alerta Thompson ${ }^{13}$.

É preciso compreender a natureza do problema, conceituando-se assim as transformações nas relações sociais, econômicas, culturais e de poder na sociedade mundializada deste novo milênio. Esta análise deve ainda considerar que uma nova identidade está se formando entre os usuários das NTIC, que permeiam a vida cotidiana. Por identidade estamos entendendo os arcabouços culturais, econômicos, políticos, lingüísticos diferenciados do existente e que formam as estruturas de valores, comportamentos, ações e representações que influenciam e determinam as relações sociais (no sentido mais amplo possível) entre os indivíduos participantes da rede, os que estão fora dela e as instituições produtoras de comunicação de massa.

As NTIC, particularmente a internet, têm forçado os profissionais da área da comunicação e da educação a se debruçarem em busca da compreensão desses novos paradigmas.

Como apontam as reflexões realizadas neste artigo, entendemos que tal compreensão passa pela necessidade de se definir e desvendar a identidade ou as várias identidades dos usuários das Novas Tecnologias de Informação e Comunicação - NTIC. Estamos diante de um processo que poderá alterar por completo quem passará a deter a informação daqui por diante.

Temos de estar atentos à questão do poder de concentração de conteúdo sobre a rede e mesmo da formação e atuação dos grandes conglomerados transnacionais de comunicação. Acreditamos, neste primeiro momento, que o caráter das megafusões entre as grandes empresas da mídia determinará, sem dúvida, a configuração social deste novo milênio. Cabe, principalmente, neste contexto, aos educadores e comunicadores, um alerta para o perigo deste processo e com isso tentar buscar alternativas, através de grupos organizados, que preservem o uso democrático das NTIC. Devemos reconhecer que as novas tecnologias trazem em seu bojo possibilidades bastante interessantes de instrumental educativo e comunicativo. Quem determinará qual caráter irá prevalecer será a própria sociedade e as forças políticas e econômicas que contornam tal fenômeno. 
Resumo: As novas tecnologias da informação e comunicação (NTIC) alteram o modelo tradicional da emissão e recepção das informações veiculadas pelas mídias tradicionais - impressos, rádios e TVs -, propiciando o surgimento de novos personagens emissores de informação, que, capacitados tecnologicamente, podem romper com o paradigma de quem detém o poder de emitir as informações. Neste sentido, a Internet, mídia que melhor representa a revolução tecnológica dos meios de comunicação, criou um novo personagem gerador de informação: o internauta. Perceber o potencial deste fenômeno e as mudanças que poderá gerar na recepção dos meios tradicionais de informação exige dos pesquisadores, principalmente das áreas de educação e comunicação, uma atenção redobrada para o estudo desse fenômeno.

Palavras-chave: tecnologia de informação e comunicação, Internet, poder, cultura global.
Abstract: New Information and Communication Technologies (NICT) change the traditional pattern of emission and reception of information carried by traditional media - printed material, radio and television -, allowing the appearance of technologically enabled information agent emissors, which can break the paradigm of the one who holds the power of emitting information. In this sense, the Internet, the media that best represents technological revolution, created a new character that generates information: the internaut. Perceiving this potential and the changes that it could generate in the traditional media reception demands, some researches, mainly on Education and Communication areas, increased their attention to the study of this phenomenon.

Keywords: information and communication technology, Internet, power, global culture. 